(7) Both the Station and the Bureau shall be free to use in official correspondence and in publications the results obtained in the investigations, proper credit to be given to the fact that such results have been obtained from the cooperative work. In case of publications, the Minnesota Agricultural Experiment Station shall give preference to results that are of interest to the State of Minnesota, and the Bureau of Plant Industry shall give preference to results that are of interest to the general region in which the crop or crops under consideration are grown. The Station shall also furnish to the Bureau when required suitable reports covering the cooperative work for publication, said reports to cover the work done according to this understanding.

(8) It is understoood that nothing herein contained shall be construed so as to in any way interfere with work that is already in progress or planned by the Bureau or the Station.

(9) The Station agrees that the rights and interests of the originators or introducers of each valuable variety shall be respected, and, so far as practicable, the time and manner of distributing such variety shall accord with the wishes of the originator or introducer.

(10) All employees of the Minnesota Agricultural Experiment Station accepting appointment from the Bureau of Plant Industry in connection with this cooperative work shall be subject to the Station and shall accept appointment only as approved by the head of the Station.

( Signed)

WM. M. LIGGETT,

Director, Minnesota Agricultural Experiment Station.

B. T. Galloway,

Chief, Bureau of Plant Industry.

The following contribution to this report was submitted by W. M. Munson, of the Agricultural Experiment Station, Orono, Me.:

\title{
COOPERATIVE BREEDING OF SMALL FRUITS-WHAT HAS BEEN DONE; WHAT CAN BE DONE.
}

In the breeding of plants, as of animals, the personal equation of the breeder enters very largely into the problem, and it is very seldom that two people can be brought together who will look upon a given problem from the same point of view. Many an enthusiastic plant breeder has laid well his plans, and distributed seeds or plants to widely separated districts, in the hope of solving some of the problems which have puzzled horticulturists for many years, only to find that, at the end of one, two, or at the most, three years, the work in which he himself had been so deeply interested had been side-tracked by the cooperating parties because of local conditions or flagging interest. As a result of several such experiences, the writer was soméwhat skeptical in regard to the practicability of cooperative work in the breeding of small fruits, and accordingly enlisted the assistance and experience of several leading horticulturists, from all parts of the country, in an attempt to arrive at some common ground which should be in advance of the present knowledge of the subject.

Almost invariably the experience of station horticulturists. in cooperating with the average farmer has been disastrous. In West Virginia some years ago Doctor Myers found as a result of trusting to 
the cooperation of farmers that but one out of 708 experimenters in wheat made any attempt to carry out instructions, and his conclusion as a result of this bitter experience conforms to that of every other careful breeder: - Experimental work must not be entrusted to persons unfamiliar with scientific methods.

I give below, without using the names of correspondents, a brief summary of replies received in answer to questions asked relative to experience in cooperative breeding and the practicability of future work in this direction:

Work done.

No cooperative work undertaken.

\section{Suggestions.}

Cooperation in the selection of seedlings is the only practicable line.

COLORADO.

Nothing has been done or is being done in Colorado.

Does not believe cooperative work at all practicable, except in testing new kinds.

CANADA.

Very little has been done except to send seedlings or new varieties to individuals for further test.

The main value of cooperative work in breeding small fruits will be in finding the adaptability of different new varieties to a wide range of climatic conditions.

\section{MICHUGAN}

Nothing done except to test new varieties and aid originators to disseminate them.

Cooperation between stations and individuals may be very helpful in testing a given variety under different conditions.

\section{Canada.}

Work of variety testing very extended; about 2000 growers con. ducting tests and reporting annually. This includes tests of Station seedlings and varieties received from originators. Effort made to induce cooperative growers to select individual trees and plants for propagation and development of improved strains.

MICHIGAN.

Has arranged program looking to assistance from State Horticultural Society. Will place promising seedlings with members of the Society for trial and encourage individual selection.

Believes cooperation practicable along lines indicated, but would not depend upon. the general growers beyond this; though there may be occasional men who are capable of such assistance.

Believes cooperative work in breeding small fruits practicable if the cooperator is reliable. Would make a duplicate statement of work to be done and directions for carrying it out.

MUNNESOTA.

Has encouraged raising of seed- The principal value of cooperaling fruits by offering premiums. tion is in educating public sentiment. 
IOWA.

Varieties are tested at the experiment station and distributed to branch testing stations for trials under different conditions.
Under proper management cooperative breeding of small fruits is practicable. If proper men can be secured to assist, cooperative work is a great advantage over local work at the experiment station in determining merits of any given fruit.

VERMONT.

So far no work has been done along this line.
As a rule, cooperative work with individuals, unless in exceptional cases, is not satisfactory. Does not know a single person in this State who is actually breeding small fruits.

NEW YORK.

Does not know of any cooperative experiments in breeding small fruits.
Sees no reason why cooperative work in breeding small fruits is not feasible. The principal difficulty. lies in finding the man who is in: terested in it and deciding upon lines of work equally valuable in different sections of the country.

\section{MASSACHUSETTS.}

Cooperation is of value in testing the value of new varieties, but no successful cooperative plant breeding arrangement is known.
Plant breeding, either for fruit or flowers, is for the most part a labor of love. Carefully bred seed and young seedling plants should not be subjected to the liability of neglect incident to being "farmed out."

From the above it is evident that there is a widespread lack of cooperation at present, and a general feeling that such work, aside from variety testing, is impracticable. The frank avowal of one correspondent from Massachusetts- "Don't know a thing about it"-very nearly covers the ground of past experience in the direction of cooperative breeding of small fruits.

As to the future, little more can be said. The obstacles have already been pointed out. In the judgment of the writer, cooperative breeding of fruits, aside from mere variety testing, as already suggested, must be restricted to such work as can be placed under the general supervision of the United States Department of Agriculture. Arrangements may be made for the details of propagation and culture, but notes and observations must be made by the same individual in different localities, in order to avoid the personal element. In the details of propagation and culture, too, there is great danger of error, from the inevitable lack of individual interest in the problem under consideration.

Among some of the problems incident to the improvement of small fruits which may possibly to a greater or less extent be taken up in a cooperative way are: (1) The development by selection of disease- 
resistant types; (2) the improvement of types by selection of bud variations; (3) the crossing of species and varieties, and the subsequent fixation of new types; and (4) the development of types suitable for southern conditions. Aside from these and a few similar questions, it would seem that the problem of small-fruit breeding must be solved by individual rather than by cooperative effort.

\section{PREVENTION OF DEGENERATION THE ONIY PRACTICAL EUGENICS.}

By. Chas. E. Woodruff, M. D., Plattsburg Barracks, N. Y.

The word eugenics has been so misunderstood that it would be better to substitute an English equivalent which is in common everyday use- "good bringing up." In the first place, whenever the idea is suggested that some means must be taken to lessen the terrible modern burden of the pauper, insane, defective, and criminal, and that the race must be made better, it is at once imagined that the only way to do it, is by copying the methods of the plant and stock breeder. Although these methods are hopelessly out of the question, the full absurdity of applying them to man is not realized until the matter is explained. Luther Burbank, for instance, by the use on a grand scale of methods long known and practiced by other plant breeders, has accomplished very marked results in "improving" his varieties. He finds a few variations among say a hundred thousand specimens, saves these two or three and kills the rest. It has been seriously stated that such success shows what we could do in the case of mankind, as though it were possible for us to keep a few men and women for matrimony and destroy the rest or sterilize them.

The selection of life partners is under the influence of laws which we do not pretend to understand but which we cannot disturb. The only thing known about the matter is a greater or less tendency found, in common with some of the domestic animals, to mate with opposites. It seems to be an inherited instinct and due to the fact that the offspring are thus kept nearer to the average--such specimens being better fitted for survival than those which vary too much. The whole animal world thus in time becomes descended from parents having this tendency to keep species together and not to scatter them. New types arise only when new variations are produced from other causes and are better fitted for survival or at least not unfitted. In man as in other species, the immense majority of variations are predestined to disappear. Old types, if adjusted to the environment, survive in remarkable purity. The peasant of the Nile, for instance, though repeatedly conquered and mixed with other types is identically the same as pictured on the oldest monuments.

The tendency of man, as well as the higher animals, is of course to mate in his own species and in the vast majority of cases, in his own 